insulating materials field, speeial account is being taken of the latest developments in plastics.

A new section with appropriate sub-committees has been set up to deal with problems of transformer engineering arising especially from war-time and post-war requirements. An exhaustive account has been published of seven years investigation for the Central Electricity Board on surge phenomena, and work has been carried out at the National Physical Laboratory on the surge properties of insulating materials and the surge resistance of tower footings. Researches on conductors, earthing, continuity and on electric control apparatus continue, and the hard gas eircuit breaker is receiving special attention. The work of the Association on the application of electricity to agriculture and horticulture continues and is beginning to receive wider recognition in those circles.

The report discloses that the work of the Association is now carried on by no less than 109 technical sections, sub-committees and panels, comprised of experts engaged in industry and in universities and other training institutions. Eighty-three technical reports, relating to a wide variety of subjects, have been issued by the Association during the year, and thirty others were in an advanced stage of preparation at the end of the year. The Association has been recognized as an essential undertaking and a closer liaison has been developed during the year with the Ministry of Supply and, to a lesser degree, with the Fighting Services. The activities of the Information Bureau and Library have been increased by wartime requirements, and work on a complete analytical index to reports of the Association has been carried on during the year. The report is an encouraging survey of the researches which are being undertaken for the electrical industry to meet the needs, not only of war-time requirements, but also of the post-war reconstruction period. It is rightly considered that particular importance should be attached to reconstruction problems, which should receive adequate and timely attention from the point of view of research as new ideas, findings and methods must be absorbed by industry long before research results are needed in commereial enterprises.

\section{Agricultural Meteorology in India}

THe annual report of the Agricultural Meteorology Section, India Meteorological Department, for the year 1939-40 covers the last year during which the section was being financed by the Imperial Council of Agricultural Research, the Government of India having taken over the Section from April 1, 1940. The report describes a number of investigations, most of them concerned with the micro-climatology of crops, that is, with the climates experienced within growing crops, as distinct from the more artificial climate of the ordinary meteorological instrument enclosure which is of greater interest for comparisons between the climates of different countries. A number of new instruments have been developed, including several forms of portable but accurate galvanometer for use with thermocouples of copper and constantan for the measurement of temperature in microclimatology. The recently completed 35 -ft. tower at the Central Agricultural Meteorological Observatory at Poona has been found very useful for mounting thermographs, hygrometers and anemometers, for studies of the variations of temperature, humidity and wind with height, which are important in the control of the vertical exchange of heat and moisture between the soil and the overlying air. At Poona, insolation even in January is found to be so strong that the convective layer, with temperature decreasing with height, does not normally disappear during the night, and is generally still to be observed as a layer one or two feet thick at 6 a.m., when temperature in the lower layers is near its minimum. At that time it is generally coldest at a height of one or two feet, with temperature increasing upwards from that level for several hundred feet, the rise amounting already to about $3^{\circ} \mathrm{C}$. on reaching the top of the 35-ft. tower. By April the greater insolation is more than counteracted in its tendency to maintain the convective layer by the effect of a higher average nocturnal wind speed, the net result being that the layer has almost disappeared by 6 a.m. The report includes a number of other studies relating to micro-climatology, among which is a table showing the average wind speed in the afternoon at various heights up to $8 \mathrm{ft}$. in eight different crops, expressed as a percentage of the wind at the same height above open ground. Up to $2 \mathrm{ft}$., wheat and sugar cane show the highest degree of sheltering, tobacco and suran the least.

\section{Nobel Laureates in the United States}

THE philanthropy of Alfred Nobel, the Swedish industrialist, is usually commemorated on December 10 in Stockholm or Oslo with the announcement of the new Nobel Prize winners. In its place a dinner was held in the United States on December 11 at which eleven Nobel laureates were guests of honour. The celebration marked the fortieth anniversary of the first awards. Nobel laureates who were present at the dinner included Dr. Viktor F. Hess, Dr. C. J. Davisson, Prof. Enrico Fermi, Prof. Otto Meyerhof, Dr. Karl Landsteiner, Dr. Irving Langmuir, Prof. H. C. Urey and Prof. Peter J. W. Debye. Dr. Vilhjalmur Stefansson presided.

\section{Medical Research Council: Radiotherapeutic Research Unit}

The Medical Research Council announces that its Radiotherapeutic Research Unit (formerly Radium Beam Therapy Research) has now resumed clinical work in new quarters which have been provided by the London County Council at Hammersmith Hospital. For the present, this work will be confined to the treatment, by radium beam therapy or X-rays, of cases of carcinoma affecting the buccal cavity, tongue, pharynx and larynx. The director, Dr. Constance A. P. Wood, would be glad to have suitable cases referred to her: these should be patients who have had no previous treatment, either surgical or radiological, and preferably not in a very advanced stage of the disease. The physical work under the charge of Mr. L. G. Grimmett, which has meanwhile been continued in temporary quarters at the Imperial College of Science and Technology, has also been transferred to Hammersmith Hospital.

\section{American Chemical Society: New President}

Dr. Per K. Frolich, director of the Chemical Division of the Esso Laboratories of the Standard Oil Development Company at Elizabeth, N.J., known for his work in the development of synthetic rubber, has been elected president of the American Chemical Society for 1943. Dr. Frolich took 